BMJ Open

Diabetes

Research

\& Care

\title{
Provider beliefs about diabetes treatment have little impact on glycemic control of their patients with diabetes
}

\author{
Erin S LeBlanc, ${ }^{1}$ A Gabriela Rosales, ${ }^{1}$ Sumesh Kachroo, ${ }^{2}$ Jayanti Mukherjee, ${ }^{2}$ \\ Kristine L Funk, ${ }^{1}$ Jennifer L Schneider, ${ }^{1}$ Gregory A Nichols ${ }^{1}$
}

To cite: LeBlanc ES, Rosales AG, Kachroo S, et al. Provider beliefs about diabetes treatment have little impact on glycemic control of their patients with diabetes. BMJ Open Diabetes Research and Care 2015;3:e000062. doi:10.1136/bmjdrc-2014000062

- Additional material is available. To view please visit the journal (http://dx.doi.org/ 10.1136/bmjdrc-2014000062)

Received 23 September 2014 Revised 8 December 2014 Accepted 6 January 2015

CrossMark

\section{${ }^{1}$ Kaiser Permanente Center for Health Research, Portland, Oregon, USA ${ }^{2}$ Bristol-Myers Squibb, Wallingford, Connecticut, USA}

Correspondence to Dr Erin S LeBlanc; Erin.S.LeBlanc@kpchr.org

\section{ABSTRACT}

Objective: To improve the health of people with diabetes, it is essential to identify why patients experience extended periods of poor glycemic control before therapeutic intensification.

Research design and methods: We surveyed 252 primary care providers at Kaiser Permanente Northwest to determine their beliefs about the glycemic goals of their patients, treatment intensification behavior, and barriers to achieving optimal glycemic control. We linked the responses of 149 providers to the health records of their 18346 patients with diabetes.

Results: Patient glycemic levels were not related to either individualized glycemic goals or provider intensification behavior. Providers' beliefs about diabetic treatment and glycated hemoglobin (HbA1c) goals were poorly associated with patient $\mathrm{HbA1c}$ levels. Providers identified patients' resistance to lifestyle behaviors and taking insulin, lack of medication adherence, and psychosocial issues as the main barriers to optimal glycemic control. Lack of time to care for complex patients was also a barrier. Providers who agreed that "current research did not support A1C levels $<7 \%$ " were less likely to have patients with HbA1c levels $<7 \%$ (OR=0.87, $95 \% \mathrm{Cl} 0.78$ to 0.97 ) and patients of providers who disagreed that "some patients will have an $\mathrm{A} 1 \mathrm{C}>9 \%$ no matter what I do" were $16 \%$ more likely to have patients with $\mathrm{HbA1c}$ $<7 \%(1.16,1.03$ to 1.30$)$ compared with providers who were neutral about those statements.

Conclusions: Given the consistency of $\mathrm{HbA} 1 \mathrm{c}$ levels across providers despite differences in beliefs and intensification behaviors, these barriers may be best addressed by instituting changes at the system level (ie, instituting institutional glycemic targets or outreach for dysglycemia) rather than targeting practice patterns of individual providers.

\section{INTRODUCTION}

Type 2 diabetes is a progressive disease that requires ongoing treatment intensification to achieve and maintain glycemic control. ${ }^{1}$ Only $53 \%$ of people with diabetes in the USA between 2007 and 2010 had the American Diabetes Association's recommended glycated hemoglobin (HbAlc) levels of less than 7\%. ${ }^{23}$

\section{Key messages}

- Patients' glycated hemoglobin levels are consistent across providers despite differences in providers' beliefs and treatment intensification behaviors.

- From the providers' perspectives, lack of time with patients as well as patients' resistance to healthy lifestyle behaviors and insulin use, poor compliance, and psychosocial issues contribute most to poor glycemic control.

- Addressing barriers to optimal glycemic control may be best done at the health system level rather than through intervention at the individual provider level.

Studies suggest that approximately $50-60 \%$ of patients with HbAlc levels above goal are not being prescribed a change in therapy or are actually having their therapy decreased, ${ }^{4} 5$ despite several therapeutic guidelines for managing hyperglycemia. ${ }^{6-8}$ One factor that has been cited for driving this lack of therapy intensification is 'clinical inertia', defined as a clinician recognizing a problem but failing to act. ${ }^{9} 10$

Delays in treatment intensification lead not only to long ( $>12$ months) periods of hyperglycemia, but also to a lower likelihood of therapeutic success once therapy is intensified. ${ }^{11-16}$ However, analyses of administrative data that identify clinical inertia when the HbA1c exceeds a guideline-level recommendation may not adequately account for mitigating factors that affect clinician decision-making. Indeed, current guidelines suggest that patient characteristics such as older age, frailty, or multiple comorbidities may be legitimate reasons for delaying therapy intensification. ${ }^{3} 1718$ In addition, clinician beliefs about the importance of glycemic control, especially in the context of these patient characteristics, may help explain why apparent clinical inertia is, in fact, clinical decisiveness. Therefore, to better understand the reasons why providers do and 
do not take action when their patients are not at glycemic goal, we conducted a study that taps into an often overlooked source of information-the providers themselves -and linked their responses to actual patient data extracted from electronic medical records.

\section{METHODS}

\section{Setting}

Kaiser Permanente Northwest (KPNW) is a not-for-profit, group-model health maintenance organization that provides integrated, comprehensive medical care to about 490000 individuals in a 75-mile radius around Portland, Oregon. Primary care providers (PCPs) include physicians, nurse practitioners, and physician assistants of Internal Medicine and Family Practice departments. Patients select a personal PCP, although they are also free to visit other clinicians for short-notice appointments or when their PCP is not available. All patients with a selected PCP are called that PCP's 'panel'.

\section{Overall study design}

The study was executed in three phases. In the first phase, we conducted $45 \mathrm{~min}$ qualitative interviews with 12 PCPs. Guided by the interview findings, we developed a questionnaire that was fielded to all KPNW PCPs (phase 2). In phase 3, we linked the electronic medical records of patients with diabetes to the panels of PCPs who responded to the questionnaire to ascertain individual patient and overall panel glycemic control.

\section{Phase 1: Qualitative interviews}

We created lists of PCPs who had 'high', 'medium', and 'low' performance based on the proportion of patients with diabetes with HbAlc levels $<7 \%$, proportion of patients with diabetes with HbA1c levels $>7 \%$ who were on diabetes medications, and the mean time to diabetes medication initiation after an HbAlc level $>7 \%$. We randomly approached by email PCPs from each of the three groups on the list, inviting them to participate in the structured, open-ended interview about their approach to diabetes therapy and glycemic control. Recruitment continued until we met our goal of 12 interviews, 4 from each group. A trained qualitative interviewer (JLS) conducted the interviews using a guide developed by the research team. Interview data were analyzed by JLS using a content analysis approach $^{19-21}$ During recruitment, conducting, and analysis, both the interviewer and the participant remained unaware as to the group from which the PCP was drawn.

On the basis of data from the qualitative interviews (online supplementary table S1), we developed a short survey that could be completed in 5-10 min. Survey questions focused on glycemic goals, barriers to achieving those goals, triggers for intensification of pharmacological therapy, and opinions about goal HbAlc levels and diabetes therapy.

\section{Phase 2: Survey of providers}

We sent email invitations to 252 KPNW primary care clinicians to participate in the survey (online supplementary figure S1) and received 124 responses. After no response to three email reminders, we sent paper copies of the survey via interoffice mail and obtained 57 additional responses, an overall response rate of $72 \%$ $(n=181)$. Of the 181 respondents, 14 returned blank surveys and 18 did not provide their clinician identifiers (necessary for linking purposes) or had fewer than 20 general patients and/or 3 patients with diabetes on their panel, leaving 149 analyzable and linkable respondents (59\% of the total survey sample).

\section{Phase 3: Linkage to patient-level data}

We identified all patients who were on PCP panels and were known to have diabetes at the time of the survey distribution (August 2013). We collected the patient HbAlc value closest to this date.

\section{Statistical analyses}

Descriptive statistics were summarized by mean and SD values and by numbers and percentages. We categorized patients' mean HbAlc values according to commonly used cut-points $(<7 \%, 7-7.9 \%, \geq 8 \%)$. We calculated the percentage of each PCP's panel of patients with diabetes that was within these cut-points.We also averaged together the HbAlc values of the PCP's panel of patients with diabetes. For specific questions, we first identified the number of PCPs who answered those questions in a particular way; then, among those PCPs who answered in that way, we reported the mean HbA1c values of their patients and/or the mean percentage of their patients who had HbAlc values within the following cut-points: $<7 \%, 7-7.9 \%$, or $\geq 8 \%$. We used hierarchical generalized linear models to assess providers' beliefs about diabetic treatment and HbAlc goals as predictors of their patient's HbAlc levels. All models were adjusted by their panel's age and gender characteristics and were the level-1 variables in the models (online supplementary material: Summary of an HGLM model). The PCP's responses to the survey questions were used as level-2 variables in the models. Analyses were conducted using SAS V.9.2 (SAS institute, Cary, North Carolina, USA) and HLM 7 for Windows (Scientific Software International, Inc., Lincolnwood, Illinois, USA).

\section{RESULTS}

\section{Baseline characteristics}

In phase 1, 12 PCPs were interviewed; 252 were sent surveys during phase 2, and 149 were analyzed in phase 3 (table 1). The PCPs in each phase had generally similar demographics: the average age was 44 in phase 1 and 47 in phases 2 and 3 , and $42 \%, 46 \%$, and $50 \%$ were male, respectively. There was a higher percentage of internal medicine physicians among those surveyed in phase 1 and a lower number of patients with diabetes 
Table 1 Baseline characteristics of PCPs

\begin{tabular}{|c|c|c|c|}
\hline & Interviewed & Surveyed & Analyzed \\
\hline Number of PCPs & 12 & 252 & 149 \\
\hline Age (mean $\pm S D)$ & $44 \pm 5$ & $47 \pm 9$ & $47 \pm 9$ \\
\hline Male (\%) & 41.70 & 46.00 & 50.3 \\
\hline Internal medicine (vs family practice) (\%) & 75 & 50 & 50 \\
\hline MD (vs physician assistant/nurse practitioner) (\%) & 91.7 & 96.4 & 97.3 \\
\hline Number of diabetes patients per PCP (mean \pm SD) & $130 \pm 91$ & $96 \pm 68$ & $131 \pm 71$ \\
\hline Total number of patients with diabetes for all PCPs combined & 1562 & 21919 & 19527 \\
\hline Age of patients (mean $\pm S D$ ) & $64 \pm 2$ & $64 \pm 4$ & $62 \pm 4$ \\
\hline $\mathrm{HbA} 1 \mathrm{c}$ of patients (mean $\pm \mathrm{SD}$ ) & $7.2 \pm 0.1$ & $7.3 \pm 0.5$ & $7.2 \pm 0.3$ \\
\hline
\end{tabular}

$\mathrm{HbA1c}$, glycated hemoglobin; MD, medical doctor; PCP, primary care providers.

per provider in the entire survey population (phase 2) compared with the phase 1 or phase 3 providers.

\section{Phase 1: Qualitative interviews of 12 providers}

From the qualitative interviews, we identified several themes related to diabetes treatment: patient-level barriers to optimal control, care-setting barriers to optimal control, patient factors that influence glycemic goals, facilitators to optimal control, and follow-up and outreach approach with patients at different HbA1c levels (online supplementary table S1).

\section{Phase 2: Survey of providers}

The complete survey and response frequencies are shown in online supplementary table S2. The three primary domains captured in the survey are described below.

Barriers to optimal glycemic control: The most commonly identified patient-related barriers (the majority of PCPs stated that the factor contributed $\geq 50 \%$ of the time) were psychosocial issues, resistance to lifestyle change, and non-compliance; the most common caresetting issue was lack of provider time to care for complex patients. The moderately common factors $(>1 / 3$ providers stated that the factor contributed $\geq 50 \%$ of the time) were patients' unwillingness to use insulin and competing organizational demands on providers. The least common factors $(<1 / 3$ providers stated that the factor contributed $\geq 50 \%$ of the time) included costs of treatment, cultural issues, other medical issues that took precedence, and a limited formulary.

Issues that delay pharmacological intensification: The most common factors ( $\geq 25 \%$ of the time) were resistance to lifestyle change and non-compliance. Unwillingness to consider insulin and psychosocial issues were less common factors ( $\geq 15$ to $<25 \%$ of the time), as were older age and other medical problems that took precedence $(\geq 10$ to $<15 \%$ of the time). Side effects of medicines, costs of medicines, cultural issues, and a lack of established patientprovider relationship contributed only a small amount of the time ( $\geq 5$ to $<10 \%$ of the time).

Opinions about diabetes treatment: $80 \%$ of PCPs stated that they allowed patients who were above their individualized glycemic goal to work on lifestyle changes for 3-6 months before prescribing a pharmacological change; only $4 \%$ stated that they waited $>6$ months before making a pharmacological change. Eighty per cent of PCPs agreed that older patients need less stringent HbAlc goals. Almost all PCPs agreed that weight loss was a critical component of diabetes care, but only $40 \%$ agreed that the manner in which a diabetes medication affects weight influenced their therapy decisions.

\section{Phase 3: linking PCP responses to patient level data}

Glycemic goals: Table 2 shows the number and percentage of responding PCPs who reported that none or very few $(<10 \%)$, some $(10-40 \%)$, about half $(41-60 \%)$, most $(61-90 \%)$, or nearly all $(>90 \%)$ of their patients had HbAlc goals of $<7 \%$ or $7-7.9 \%$. Also displayed is the percentage of PCPs' panels with actual HbAlc levels of $<7 \%$ and $7-7.9 \%$. For example, $61(42 \%)$ providers reported that most of their patients had an HbAlc goal $<7 \%$. Among those 61 providers, a mean of $56 \%( \pm 0.07 \%)$ of their panel had HbAlc levels $<7 \%$. The percentage of providers' patients who were $<7 \%$ or $7-7.9 \%$ was similar among providers despite different individualized glycemic goals in their respective panels of patients.

HbA1c triggers for intensification: For their patients who were already on one oral hypoglycemic agent, 45 $(33 \%)$ providers reported that their trigger for a medication change was one HbAlc test result at least $0.5 \%$ above goal (table 3). The mean HbAlc of the patients of these 45 PCPs was $7.2 \%( \pm 0.2 \%)$, and on average $55.6 \%( \pm 0.07 \%)$ of their panels had HbAlc values $<7 \%$. Based on the results of the hierarchical linear models, there was no statistically significant association between the HbAlc trigger and the odds of patients achieving glycemic goals. As an illustration, $13(9 \%)$ providers reported that they would make a medication change when two HbAlc values were at least $1 \%$ above goal. The glycemia of the patients of these 13 PCPs (mean HbAlc $7.3 \%( \pm 0.3 \%)$ with a mean of $53.7 \% \quad( \pm 0.06 \%)$ having HbAlc values $(<7 \%))$ was similar to the 45 PCPs whose medication trigger was more stringent.

Opinions about diabetes treatment: Table 4 shows the proportion of respondents who agreed or strongly agreed with four statements about HbAlc levels, and the proportion that disagreed or strongly disagreed with a fifth statement. Also shown is the mean HbAlc of the 
Table 2 PCPs' reports on how many of their patients have certain glycemic goals compared with how many of their patients actually achieve those goals

\begin{tabular}{|c|c|c|c|c|}
\hline & $\begin{array}{l}\text { PCPs' reports of } \\
\text { how many of their } \\
\text { patients have an } \\
\text { HbA1c goal of }<7 \% \text { * } \\
\mathrm{N}=144 \\
\mathrm{~N}(\%)\end{array}$ & $\begin{array}{l}\text { Percentage of PCPs' } \\
\text { patients who have an } \\
\text { HbA1c goal of }<7 \% \\
\text { Mean } \pm \text { SD }\end{array}$ & $\begin{array}{l}\text { PCPs' reports of how } \\
\text { many of their patients } \\
\text { have an HbA1c } \\
\text { goal of } 7-7.9 \%{ }^{*} \\
N=136 \\
N(\%)\end{array}$ & $\begin{array}{l}\text { Percentage of PCPs' } \\
\text { patients who have an } \\
\text { HbA1c goal of } \\
7-7.9 \% \\
\text { Mean } \pm \text { SD }\end{array}$ \\
\hline $\begin{array}{l}\text { None or very few }(<10 \%) \text { of their patients have this } \mathrm{HbA} 1 \mathrm{c} \\
\text { goal }\end{array}$ & $12(8)$ & $56.3 \pm 0.08$ & $12(9)$ & $22.8 \pm 0.04$ \\
\hline Some $(10-40 \%)$ of their patients have this $\mathrm{HbA} 1 \mathrm{c}$ goal & $21(15)$ & $54.0 \pm 0.05$ & $85(63)$ & $22.8 \pm 0.05$ \\
\hline About half $(41-60 \%)$ of their patients have this $\mathrm{HbA} 1 \mathrm{c}$ goal & $29(20)$ & $54.9 \pm 0.08$ & $21(15)$ & $23.2 \pm 0.05$ \\
\hline Most $(61-90 \%)$ of their patients have this $\mathrm{HbA} 1 \mathrm{c}$ goal & $61(42)$ & $56.0 \pm 0.07$ & $17(13)$ & $24.6 \pm 0.06$ \\
\hline Nearly all $(>90 \%)$ of their patients have this $\mathrm{HbA1c}$ goal & $21(15)$ & $52.4 \pm 0.05$ & $1(<1)$ & 23.2 \\
\hline
\end{tabular}

Table 3 PCPs' reports of what HbA1c elevation triggers them to intensify pharmacological therapy compared with how many of their patients have various $\mathrm{HbA1 \textrm {c }}$ levels

\begin{tabular}{|c|c|c|c|c|c|}
\hline Reported trigger for intensification & $\begin{array}{l}\text { Proportion of PCPs } \\
\text { reporting this } \\
\text { HbA1c trigger } \\
\mathrm{N}=139 \\
\mathrm{n}(\%)\end{array}$ & $\begin{array}{l}\text { Mean HbA1c of } \\
\text { patients whose } \\
\text { PCPs report this } \\
\text { trigger } \\
\text { Mean } \pm \text { SD }\end{array}$ & $\begin{array}{l}\text { Percentage of } \\
\text { patients } \\
\text { with } \mathrm{HbA} 1 \mathrm{c}<7 \% \\
\text { Mean } \pm \text { SD }\end{array}$ & $\begin{array}{l}\text { Percentage of } \\
\text { patients with } \\
\text { HbA1c of } 7-7.9 \% \\
\text { Mean } \pm \text { SD }\end{array}$ & $\begin{array}{l}\text { Percentage of } \\
\text { patients with } \\
\text { HbA1c } \geq 8 \% \\
\text { Mean } \pm \text { SD }\end{array}$ \\
\hline $1 \mathrm{HbA} 1 \mathrm{c} \geq 0.5 \%$ above goal & $45(33)$ & $7.2 \pm 0.2$ & $55.6 \pm 0.07$ & $23.0 \pm 0.05$ & $21.4 \pm 0.05$ \\
\hline $2 \mathrm{HbA} 1 \mathrm{c} \geq 0.5 \%$ above goal & $46(33)$ & $7.3 \pm 0.3$ & $54.3 \pm 0.07$ & $23.6 \pm 0.04$ & $22.1 \pm 0.06$ \\
\hline $1 \mathrm{HbA} 1 \mathrm{c}>1.0 \%$ above goal & $35(25)$ & $7.2 \pm 0.2$ & $54.9 \pm 0.07$ & $23.5 \pm 0.06$ & $21.6 \pm 0.05$ \\
\hline $2 \mathrm{HbA} 1 \mathrm{c}>1.0 \%$ above goal & $13(9)$ & $7.3 \pm 0.3$ & $53.7 \pm 0.06$ & $22.8 \pm 0.04$ & $23.5 \pm 0.07$ \\
\hline
\end{tabular}

$\mathrm{HbA1c}$, glycated hemoglobin; $\mathrm{PCP}$, primary care providers. 
patients of these PCPs, the percentage of their patients with different HbAlc levels, and the age-adjusted and sex-adjusted probability of their patients attaining HbA1c $<7 \%$ compared with patients of PCPs neutral for that statement. For example, $77 \%$ of providers agreed or strongly agreed that most patients should strive for HbAlc $<7 \%$. The mean HbA1c of their patients was $7.3 \%( \pm 0.3 \%)$, and on average $55.3 \%( \pm 0.07 \%)$ had HbAlc values $<7 \%$. However, the probability of patients of these PCPs attaining an HBA1c of $<7 \%$ was not statistically different from patients of PCPs who were neutral about this statement (OR 0.94, 95\% CI 0.80 to 1.11 ).

Two statements were associated with the probability of patients attaining an HbA1c $<7 \%$. The $21 \%$ of PCPs who agreed that "current research did not support A1C levels $<7 \%$ " were less likely to have patients with HbAlc levels $<7 \%$ compared with PCPs who were neutral about that statement $(0.87,0.78$ to $0.97 ; \mathrm{p}=0.02)$. Second, $21 \%$ of providers disagreed that "some patients will have an A1C $>9 \%$ no matter what I do." The odds of these providers' patients having an $\mathrm{HbAlc}<7 \%$ were 1.16 times (1.03 to $1.30 ; \mathrm{p}=0.01$ ) greater than the odds of patients whose providers were neutral about that statement. No other associations were statistically significant (table 4).

\section{DISCUSSION}

This novel study examined clinician-reported attitudes and beliefs about glycemic control, barriers to achieving it, and antihyperglycemic treatment intensification practices. Importantly, it also examined the association between these beliefs and actual HbAlc results of the patients with diabetes on the responding PCPs' panels. The Diabetes Attitudes, Wishes and Needs Study (DAWN) as well as DAWN2 simultaneously collected survey data from patients with diabetes and from providers. ${ }^{22}{ }^{23}$ Although patients and providers gave parallel responses to many study topics, the studies did not attempt to link patient responses directly to their own providers. To the best of our knowledge, no previous research has linked what clinicians identify as patient and care setting barriers to the documented glycemic control of their patients.

We did not find an association between patient glycemic levels and provider-reported glycemic goals or intensification behavior. Even providers' beliefs about diabetic treatment and HbAlc goals had limited associations with the HbAlc levels of their patients. These data suggest that patient and system barriers play a larger role than clinician beliefs and behaviors in prolonged poor control and delayed treatment intensification. HbAlc levels were consistent across patients despite differences in their providers' treatment behaviors, HbA1c goals, and diabetic treatment opinions.

Our interviews and surveys revealed that providers identified patient resistance to lifestyle behaviors and taking insulin, lack of medication adherence, and psychosocial issues as barriers to optimal glycemic control,

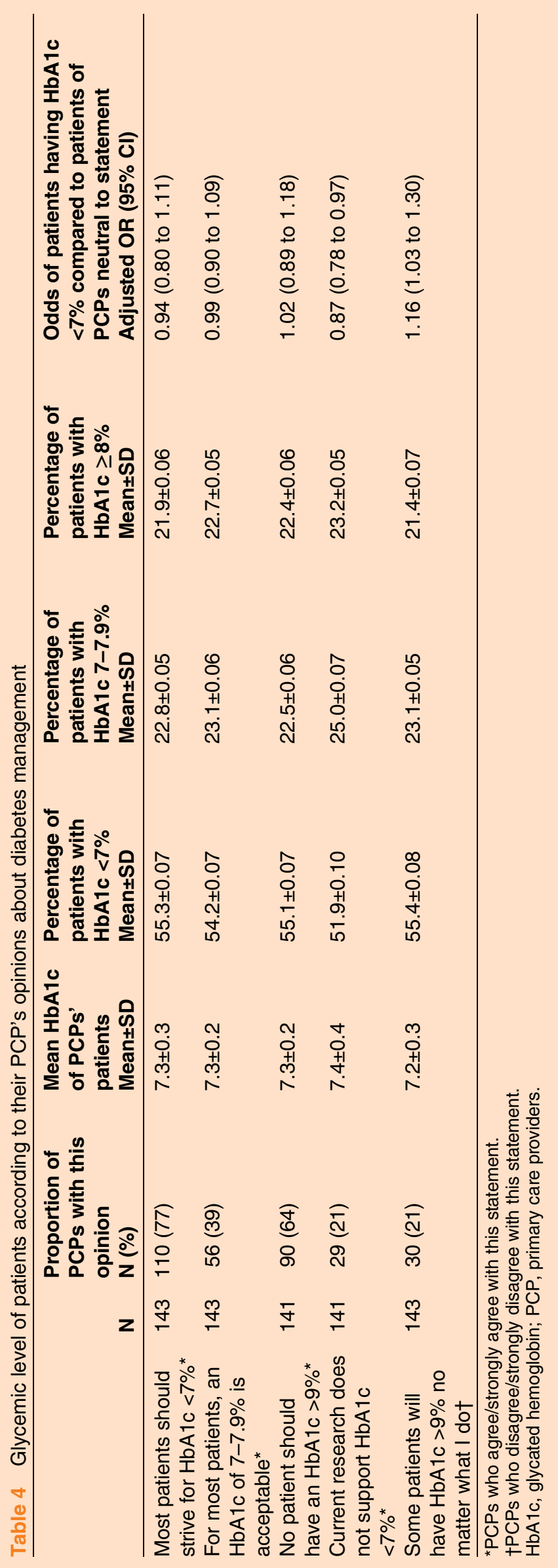


as well as lack of time to care for complex patients. These findings are consistent with concepts revealed by the DAWN study and with the notion that patients with diabetes may need greater encounter frequency or appointment length to deal with competing healthcare needs. ${ }^{24-26}$ Also, although most providers believed weight loss to be a critical component of diabetes management, most did not take into account how diabetes medications impacted patients' weight, which may contribute to the effectiveness of pharmacological therapy. ${ }^{27}$ This finding may have resulted from our health system's limited formulary. Alternatively, the development of new classes of medications that have more favorable effects on weight may be too recent to have changed the providers' approach to diabetes management. Regardless, despite differences in beliefs and intensification behaviors, HbAlc levels were consistent across providers. Taken together, it seems that intervention to reduce barriers to glycemic control directed at providers would not produce much benefit, and that addressing these barriers may be most fruitful at the health system level.

A unique strength of our study was the ability to assess clinician beliefs and then to link those beliefs to their patients' glycemic control. We achieved a relatively high response rate given the busy schedules of PCPs.

Our study had several limitations. Our analyses were hindered by a lack of variation in provider attitudes. This may be the result of conducting the study within a single organization that is highly structured and has a culture of conformity among the clinicians. Regardless of the setting, however, there may be little variation in attitudes and beliefs about glycemic control among PCPs in general. Our patient population lacked cultural diversity ( $>85 \%$ were Caucasian, non-Hispanic), which may have falsely lowered the importance of cultural issues. Indeed, in the qualitative interviews, cultural issues were often mentioned among PCPs with more diverse panels. We studied an insured population that may not represent uninsured patients or clinicians who treat them. Importantly, our restricted formulary discourages the use of newer medications that are typically more expensive than long-existing agents. This could affect the relative importance of cost issues in prescribing and intensification practices, and may also constrain our ability to assess the value of more therapeutic options. Lastly, we did not assess patient beliefs about glycemic control or attitudes about treatment intensification. Since treatment decisions are often jointly made by clinicians and their patients, our data cannot fully capture that interaction. Future work should also survey patients as patient beliefs could inform decisions about what system level programs can best improve diabetes management.

\section{CONCLUSION}

Clinicians' beliefs about glycemic goals and intensification behavior were not clearly associated with their patients' glycemia levels. Nevertheless, our findings highlighted several key factors that providers identified as driving suboptimal glycemic control including patients' resistance to lifestyle change and starting insulin, noncompliance, and psychosocial issues. It is not surprising, therefore, that providers also identified that lack of time to deal with these complex patients and their multiple issues were key reasons for prolonged suboptimal control. In the seminal paper defining clinical inertia, the authors concluded that modifying medical education to better prepare clinicians to improve management of patients with problems such as diabetes is necessary to reduce clinical inertia. ${ }^{9}$ Given the lack of association of patients' glycemia with their providers' beliefs or behaviors, our results suggest that tackling these barriers may be best done at the system level.

Contributors ESL contributed to the study conception, design, and interpretation of results, and developed the first draft of the manuscript. AGR contributed to the study conception and design, researched and analyzed the data, contributed to interpretation of results, and reviewed/edited the manuscript. SK and JM contributed to the study conception and design and reviewed/edited the manuscript. KLF and JLS contributed to the study conception and design and the discussion, and reviewed/edited the manuscript. GAN contributed to the study conception, design, and interpretation of results, and reviewed/edited the manuscript. The final draft for submission was approved by all authors. ESL is the guarantor of this work and, as such, had full access to all the data in the study and takes responsibility for the integrity of the data and accuracy of the data analysis.

Funding This study was funded by Bristol-Myers Squibb and AstraZeneca. This study was presented at the 74th Scientific Sessions of the American Diabetes Association, San Francisco, California, 13-17 June 2014.

Competing interests ESL has received additional research funding from Amgen, and GAN currently receives additional research funding from Novartis and Merck for other unrelated projects. SK and JM are employees of Bristol-Myers Squibb.

Ethics approval The study was reviewed and approved by the institutional review board of Kaiser Permanente NW.

Provenance and peer review Not commissioned; externally peer reviewed.

Data sharing statement No additional data are available.

Open Access This is an Open Access article distributed in accordance with the Creative Commons Attribution Non Commercial (CC BY-NC 4.0) license, which permits others to distribute, remix, adapt, build upon this work noncommercially, and license their derivative works on different terms, provided the original work is properly cited and the use is non-commercial. See: http:// creativecommons.org/licenses/by-nc/4.0/

\section{REFERENCES}

1. [No authors listed]. U.K. prospective diabetes study 16. Overview of 6 years' therapy of type II diabetes: a progressive disease. U.K. Prospective Diabetes Study Group. Diabetes 1995;44:1249-58.

2. Stark Casagrande S, Fradkin JE, Saydah $\mathrm{SH}$, et al. The prevalence of meeting $\mathrm{A} 1 \mathrm{C}$, blood pressure, and LDL goals among people with diabetes, 1988-2010. Diabetes Care 2013;36:2271-9.

3. American Diabetes Association. Standards of medical care in diabetes-2013. Diabetes Care 2013;36(Suppl 1):S11-66.

4. Grant RW, Cagliero E, Dubey AK, et al. Clinical inertia in the management of type 2 diabetes metabolic risk factors. Diabet Med 2004;21:150-5.

5. Shah BR, Hux JE, Laupacis A, et al. Clinical inertia in response to inadequate glycemic control: do specialists differ from primary care physicians? Diabetes Care 2005;28:600-6.

6. Nathan DM, Buse JB, Davidson MB, et al. Medical management of hyperglycemia in type 2 diabetes: a consensus algorithm for the initiation and adjustment of therapy: a consensus statement of the 
American Diabetes Association and the European Association for the Study of Diabetes. Diabetes Care 2009;32:193-203.

7. Garber AJ, Abrahamson MJ, Barzilay JI, et al. AACE comprehensive diabetes management algorithm 2013. Endocr Pract 2013;19:327-36.

8. Qaseem A, Humphrey LL, Sweet DE, et al. Oral pharmacologic treatment of type 2 diabetes mellitus: a clinical practice guideline from the American College of Physicians. Ann Intern Med 2012;156:218-31.

9. Phillips LS, Branch WT, Cook CB, et al. Clinical inertia. Ann Intern Med 2001;135:825-34.

10. Ziemer DC, Miller CD, Rhee MK, et al. Clinical inertia contributes to poor diabetes control in a primary care setting. Diabetes Educ 2005;31:564-71.

11. Brown JB, Nichols GA, Perry A. The burden of treatment failure in type 2 diabetes. Diabetes Care 2004;27:1535-40.

12. Khunti K, Wolden ML, Thorsted BL, et al. Clinical inertia in people with type 2 diabetes: a retrospective cohort study of more than 80,000 people. Diabetes Care 2013;36:3411-17.

13. Nichols GA, Conner C, Brown JB. Initial nonadherence, primary failure and therapeutic success of metformin monotherapy in clinical practice. Curr Med Res Opin 2010;26:2127-35.

14. Brown JB, Conner C, Nichols GA. Secondary failure of metformin monotherapy in clinical practice. Diabetes Care 2010;33:501-6.

15. Nichols GA, Alexander CM, Girman CJ, et al. Contemporary analysis of secondary failure of successful sulfonylurea therapy. Endocr Pract 2007;13:37-44.

16. Nichols GA, Kimes TM, Harp JB, et al. Glycemic response and attainment of $\mathrm{A} 1 \mathrm{C}$ goals following newly initiated insulin therapy for type 2 diabetes. Diabetes Care 2012;35:495-7.

17. Kirkman MS, Briscoe VJ, Clark N, et al. Diabetes in older adults. Diabetes Care 2012;35:2650-64.
18. Sinclair AJ, Paolisso G, Castro M, et al. European Diabetes Working Party for Older People 2011 clinical guidelines for type 2 diabetes mellitus. Executive summary. Diabetes Metab 2011;37(Suppl 3): S27-38.

19. Denzin N, Lincoln Y. The Sage handbook of qualitative research Thousand Oaks, CA: Sage Publications, 2011.

20. Strauss A, Corbin J. Basics of qualitative research: technniques and procedures for developing grounded theory. Thousand Oaks, CA: Sage Publications, 2008.

21. Patton MQ. Qualitative research \& evaluation methods. 3rd edn Thousand Oaks, CA: Sage Publications, 2002.

22. Peyrot M, Rubin RR, Lauritzen T, et al. Psychosocial problems and barriers to improved diabetes management: results of the Cross-National Diabetes Attitudes, Wishes and Needs (DAWN) Study. Diabet Med 2005;22:1379-85.

23. Peyrot M, Burns KK, Davies M, et al. Diabetes Attitudes Wishes and Needs 2 (DAWN2): a multinational, multi-stakeholder study of psychosocial issues in diabetes and person-centred diabetes care. Diabetes Res Clin Pract 2013;99:174-84.

24. Parchman ML, Pugh JA, Romero RL, et al. Competing demands or clinical inertia: the case of elevated glycosylated hemoglobin. Ann Fam Med 2007;5:196-201.

25. Ross SA. Breaking down patient and physician barriers to optimize glycemic control in type 2 diabetes. Am J Med 2013;126:(9 Suppl 1) S38-48.

26. Morrison F, Shubina M, Turchin A. Encounter frequency and serum glucose level, blood pressure, and cholesterol level control in patients with diabetes mellitus. Arch Intern Med 2011;171:1542-50.

27. McAdam-Marx C, Mukherjee J, Bellows BK, et al. Evaluation of the relationship between weight change and glycemic control after initiation of antidiabetic therapy in patients with type 2 diabetes using electronic medical record data. Diabetes Res Clin Pract 2014;103:402-11. 